\title{
HOW TO AUGMENT ETHICAL LEADERSHIP AND TEAM EFFECTIVENESS THROUGH EMOTIONAL INTELLIGENCE? AN EMPIRICAL ANALYSIS
}

\author{
Athar Nasir Gulzar \\ Research Scholar, National Defence University, Islamabad \\ taurus 2382@yahoo.com
}

Muhammad Zia-ur-Rehman

Associate Professor, Department of Leadership and Management Studies,

National Defence University

drziaofficial@gmail.com

\begin{abstract}
The study focuses on emotional intelligence and its vital role has been examined through which ethical leadership affects team effectiveness. In order to analyze this effect a research questionnaire was distributed amongst 300 middle level managers and supervisors of consumers' banks of twin cities i.e. Rawalpindi and Islamabad. Based on the analysis of the data collected through questionnaire it revealed that with the spiraling effect in emotional intelligence significant growth is predicted in team effectiveness. Correspondingly, a positively substantial association is also predicted of ethical leadership with team effectiveness. It further elucidates that with the evolution in ethical leadership result increases in team effectiveness. This study has exhilarating findings in the area of emotional intelligence as it signifies the importance of emotional intelligence since it further strengthens the association between ethical leadership and team effectiveness. This study also opens new dimensions in emotional intelligence research where researchers might explore how emotional intelligence affects other aspects of team effectiveness under the umbrella of ethical leadership.
\end{abstract}

Keywords: Ethical Leadership, Team Effectiveness, Emotional Intelligence

\section{INTRODUCTION}

In this research study, emotional intelligence as a fundamental influencing mechanism has been examined through which ethical leadership affects the team effectiveness. In order to analyze this effect a research questionnaire was distributed amongst 300 middle level managers and supervisors of consumers' banks of twin cities i.e. Rawalpindi and Islamabad. Based on the analysis of the data collected through questionnaire it revealed that with the spiraling effect in emotional intelligence significant growth is predicted in team effectiveness.

Correspondingly, a positively substantial association is also predicted of ethical leadership. It further elucidates that with the evolution in ethical leadership end result increases in team effectiveness. These findings are deliberated upon with context to theoretic contribution, practical inferences, and forthcoming research recommendations. The principal resolve of research work is to address the ensuing two questions. Firstly, whether and how ethical leadership maintains strong relationship and supportive to team effectiveness in this study. Secondly whether and how emotional intelligence inspires the relationship of ethical leadership and team effectiveness.

This research study aims to identify the relationship of ethical leadership and team effectiveness in the banking sector of Pakistan taking emotional intelligence as the moderator variable. This research work is unique in the sense that the study emphasis on consumers bank of twin cities i.e. Rawalpindi and Islamabad. The nature of study is primary in nature where a sample of 300 respondents including middle level managers and supervisor of the banks were taken. The outcome of this research study may well contribute to the existing facts and knowledge on team effectiveness. With the support of empirical evidence on the relationship amongst ethical leadership, team effectiveness and emotional intelligence, organizational leaders might commendably devise a strategy for professional growth programs. 


\section{LITERATURE REVIEW}

In the perspective of ethical altruism, ethical leaders maintain a conspicuous position in the organizations due to their preferment of ethical values amongst their underlings and peers alike (Brown et al., 2005). Before delving deep into the progressive evolution of ethical leadership and its paradigm, it is imperative to appreciate the term in its literal and conversational modes. The perception of ethical leadership appeared as a conspicuous theme and subject in the literature of empirical leadership, with an intense surprising acceleration in associated research since the mid-2000s.

Brown et al. have defined the term as "the demonstration of normatively appropriate conduct through personal actions and interpersonal relationships, and the promotion of such conduct to followers through two-way communication, reinforcement, and decision-making." (Brown, Trevino, \& Harrison, Ethical leadership: A social learning perspective for construct development and testing, 2005)".

By and large, ethics have been voiced as a collection of demeanors and attitudes that are believed morally and ethically 'good' and 'right' as contrary to 'bad' or 'wrong' (Simms, 1992). The very word is derived from Greek word 'Ethos' which might be interpreted as 'character'. It might also be contended that if something is characterized as morally upright and good in one state of affairs, culture and circumstances may not inexorably be regarded as identical in any other circumstances and culture.

Leadership is a process whereby an individual influences the group of individuals to achieve common goals. So ethical leadership is the process of persuading people through principles, beliefs, values whom we distinct as right behavior. Therefore $\mathrm{L}$. K Trevino maintained that 'Ethical behavior is what is considered legally and morally acceptable to the larger community' (Trevino, 1986).

Apparently, Ethical leadership encompasses multiple constituents; however, still gives the impression to be uncertain. Eminent authors of this literature maintain that ethical leadership should be viewed as facilitating and empowering others to act rightly instead of comprehending it as thwarting individuals from undertaking incongruous tasks. Predominantly, Ethical leadership seems steadfast in carrying out day to day chores of the organization in an appropriate manner. From personality perspective, ethical leaders must be confident, objective and fair minded with others and need not to be biased whatever the situation may be.

The prime professional obligation of ethical leaders is to communicate to their colleagues and down below that they must be candid, ingenuous, fair-minded and coherent \& commonsensical, wellorganized, assiduous and dependable in their day-to-day chores. Primarily Ethical leadership retorts all the core queries regarding our identity and uniqueness, what it does categorically connote, how we survive, thrive and how we have been brought up over time. Simultaneously, this also directs us the course of actions for its gradual progress to the higher level (Freeman \& Stewart, 2006).

Brown et al., (2005) maintained that ethical leaders enlighten others regarding the remunerations and rewards of ethical behavior and simultaneously, the price of incongruous conduct and attitudes. Ethical leaders also establish immaculate and untarnished criterions. Concurrently they introduce well balanced nondiscriminatory reward and punishment system to clinch subordinates liable for their ethical demeanors. Ethical Leadership is reflected as "moral umbrella" in leadership literature as it epitomizes the moral facet of leadership styles, no matter if its "value-based leadership" "authentic leadership "or "servant leadership" (Ahmad et al., 2018).

Ethical leaders are considered as effective leaders because they integrate ethics and morality in the process of decision-making process and effort optimally for rational verdicts by observing moral aspects of their pronouncements (Ciulla, 1995). Ethical Leaders enthuse encouraging conducts and comportments amongst workforces, inspire organization with heightened pride and obligation by accentuating impartial treatment, collective beliefs, and integrity in general workforces and business transactions. In addition, Ethical Leaders motivate and help employees recognize the work perspective (Piccolo, et al., 2010). Additionally, Ethical leaders being well thought-out reliable, candid, and trustworthy are reflected as a vital source of emulation (Miao et al., 2020). Subsequent to this, leaders turn out to be as genuine and trustworthy role models by following ethical conduct and demeanors (Zhao et al., 2020).

Team effectiveness being multifaceted phenomenon ardently requires a holistic and allinclusive perception by the practitioners and scholars. The pre-requisite of any organization's triumph and accomplishment is effective teams as these are considered building blocks. Team effectiveness is 
the capability and aptitude of cluster of diverse work force generally equipped with corresponding expertise, to do a job collectively to achieve objectives as assigned by a competent authority, manager, or leader of the team". Moreover, Team effectiveness models support us appreciate the finest and paramount management modus operandi to acquire optimum performance and presentation from our teams. There are 06 multiple Team Effectiveness models which include the Hackman model, the Katzenbach and Smith model, Rubin, Plovnick, and Fry's GRPI model, the T7 model, the Lencioni model and the LaFasto and Larson model.

Organizations attach all-inclusive significance to the teams because they execute vital accomplishments that lead to employees' satisfaction. However, it is also worth remembering here that employees' do not always inevitably follow right track. Moreover, they do not get contented and gratified all the time (Schermerhorn et al., 2010). In order to ensure the effectiveness of teams some criterion is imperatively required to direct the teams on the right track. A team which performs assignments with greater quantity, better quality and within prescribed time limits, moreover, participants of this team are contented and gratified, maintain mutual intent to exert on viable basis is considered as effective Team (Schermerhorn et al., 2010).

Team effectiveness thus also denotes to the mutual harmonization and synchronization of employees' job accomplishment for the sake of achievement of collective objectives or intents (Irving \& Longbotham, 2007). Since the inception of time immemorial when our forefathers got closer to each other in the pursuit of gratification of their basic necessities of life, the term teams and teamwork is enjoying worthy place (Kozlowski \& Ilgen, 2006). Moreover, teams are being reflected as nucleus in the functioning of organization as well as social organization (Gibson et al., 2007).

The research literature regarding team effectiveness endorses that team performance effectiveness can be enhanced with the manifestation of the 5 conditions such as compelling direction, real team, supportive context, competent coaching and enabling structure. There are four factors that affect the team effectiveness such as environmental influences, goals, roles and work processes. Team effectiveness refers to the system of getting people in a company or institution to work together affectively. "The team effectiveness maintains the notion behind curtain that a bunch or team of personnel organized can accomplish the objectives of the organization comparatively greater than personnel performing their work at individual level. Katzenbach and Smith (1993) maintained that rapidly growing and greater performance institutions are strongly determined on the establishment of resilient, semi-autonomous group of employees.

In an effective team, a team effectiveness audit and assessment instrument as developed by Bateman, Wilson and Bingham (2002) is deliberated as imperative as it concentrates 6 realms such as performance objectives, use of resources, skills, team synergy, innovation and quality. The assessment instrument is recognized and endorsed as an operative apparatus of networking individual as well as group performance corroborating organization's management goals. Every organization maintains vital concern regarding its team effectiveness. A normative methodology has been endorsed by Cohen, Ledford Jr, \& Spreitzer, (1996) for evaluating team effectiveness and appreciating collective performance. Team effectiveness backs system of institutions in defining the magnitude of task and product by assessing obligation, enactment, ecological issues, and voluminous of other issues (Janz, Colquitt, \& Noe 1997). Cohen \& Bailey (1997) demonstrated that collaboration and communiqué - the inbuilt team practices are considered indispensible to team effectiveness. Hu \& Liden (2011) established that empowerment of team consists of fundamentals such as a combined acceptance in the team and a joint understanding of consequence in work, is expressively associated to essentials of team effectiveness.

An enhanced appreciation of team effectiveness is a "sine qua non" for development and management of the team. Moreover, for sustenance and observation of team effectiveness its measurement is inevitable and imperative. Strategic management must essentially feel obligatory to attach much consideration to team effectiveness issues at the very preliminary stages of a team. The modus operandi to measure the performance of Team leaders and members must be well-known to them. Moreover, they must also be familiarized with the kind of support they are or can be entitled from the organization. Furthermore, it is also recommended to incorporate team members while finalizing effectiveness benchmarks as it enhances a sense of ownership amongst team participants.

In the realm of leadership literature Emotional Intelligence maintains a significant place and is deliberated upon with significant concern by the researchers (Ashkanasy \& Daus, 2002; Brown \& 
Moshavi, 2005; Cote et al., 2010; George, 2000). Emotional Intelligence (EI) is an intensely and swiftly emerging constituency of leadership study and it eventually turns out to be ardently indispensable in recognizing how folks continue with it. Emotional Intelligence expands capacity to comprehend feelings and their impression on demeanor. Peoples who maintain compact sentiments of prudence also possess a vigorous intellect to meditation, recognizing their own opinions once they experience through it (Estrada, Monferrer, Rodríguez, \& Moliner, 2021).

Emotional intelligence is rather a kind of imperceptible thing in every human being. It also guides us that how we govern and regulate our conduct, steer common complications, and conclude personal judgments that bring about encouraging effects. In the wake of which they equip themselves to make out other feelings as well as theirs own and other feelings simultaneously. Moreover, with this modus they manage huge data of files and ranks to decide judiciously (Robbins \& Judge, 2016).

Emotional Intelligence (EI) denotes as the competence to recognize, utilize, comprehend and manage emotions and emotional statistics. In the day-to-day environment, Emotional intelligence contributes significantly as to how to affects workforce and personal life. The nature of business is predominantly people oriented and when something influences the peoples it automatically affects the businesses. Every single business institute encompasses workforce of diverse nature, dispositions and sensations, which affects the pattern of work at large. The emotional intelligence is the intrinsic capability to sense, utilize, converse, distinguish, recollect, define, categorize, acquire from, organize, comprehend \& explicate the emotions (Wong \& Law, 2002).

A graduate student at doctoral level in 1985 included the term "Emotional Intelligence" for the very first time. Later after 5 years in 1990 John Mayor and Peter Salovey wrote a journal in which they included the term again. In actual they were pondering a scientific way of measuring the difference in individuals' ability in terms of their emotions. They revealed that some people are better able in understanding not their own emotions but also the emotions of other peoples (Salovey \& Mayer, 1990).

However, this term is attributed to US writer and consultant Dr. Daniel Goleman who wrote on emotional literature when he asked permission from Mayor and Salovey to include this term in his book and after their permission book named "Emotional Intelligence" came into picture by Goleman in 1995. In this book author collected and maintained information regarding brain, emotions, and behavior. The author proposed four components of emotional intelligence which includes self-awareness, selfmanagement, social awareness, and others management (Goleman, 1995).

Every soul of the world maintains this phenomenon although intangibly. However, these four constituents of Emotional intelligence further paired up into 02 competences such as personal and social competences. Personal competence further elucidates one's skill to be acquainted of your own emotions and further systematically manage one's conduct and propensities. Whereas social competence your capability to appreciate other dispositions, conduct, and intentions in order to get back to them effectually and enhance the quality association with each other. This very phenomenon also warrants effective communiqué amongst the rational and emotional centers of your brain. The better-quality level of your emotional intelligence determines your improved skill to realize and govern the motivations concerning your conduct, which ends up with the dividends accordingly.

Ample of research literature ascertains emotional intelligence as the barometer to find out brilliance and accomplishment of one's job (Lanser, 2000). Emotional Intelligence is considered as vital to commendably comprehend and maintain associations amongst human resource which is known as the bottleneck of any organization. Unluckily the term "Emotional Intelligence" has not yet been focused in Pakistani organizations however, bigger turnover rate, diverse workforce, recurrent mergers and acquisitions, globalization, variations and modifications in the work environment and competitive pressures has made it vibrant and essentially obligatory to recognize and appreciate the phenomenon. Owing to ruthless and unemotional conduct of leadership and management, many of strategic appointment holders are leaving the organizations. Moreover, diverse workforce entails emotional intelligence to face such challenge amicably in our organizations (Scarnati, 2001).

The emotional intelligence is equally significant for the personal life as well as for the organizations. The research literature has revealed that most of the work force is fired from the organization due to nonexistence of emotional intelligence rather than absence of professional expertise. Emotionally Intelligence is mandatory in true essence for the accurate managing and controlling of the workforce due to their different backgrounds. Teams implement and accomplish 
considerably well with their harmonious day to day working as well as mutual reverence for each other's emotions and feelings (Harminder, \& Jaya, 2011).

\section{THEORETICAL FRAMEWORK}

Following the previous discussion, and the proposed hypotheses, the research model (Theoretical Framework) is presented as follows.

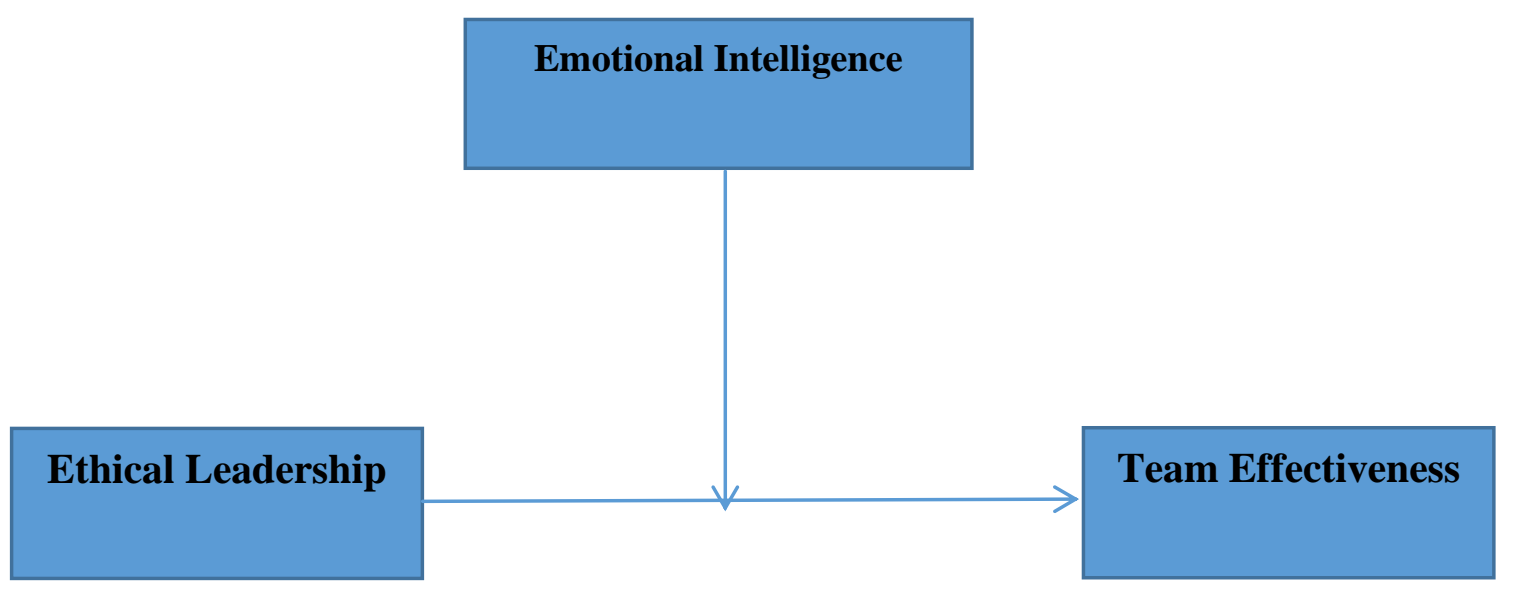

Figure 1 Theoretical Framework

In this theoretical framework Ethical Leadership is Independent Variable (IV), Team Effectiveness is Dependent Variable (DV) whereas Emotional Intelligence is the Moderator Variable (MV). We may take all the variables as per their roles in this research study. Independent and dependent variables might be considered in terms of cause and effect. Ethical Leadership being independent variable may directly impact the Team effectiveness which is dependent variable due to being affected by the independent variable and it is the variable which is being tested or measured. Moreover, independent variable is not changed by the other variables we try to measure. Emotional intelligence acts as moderator between both of variables because it strengthens the association of the independent variable upon dependent variable.

\section{Hypothesis}

Based upon the above presented framework, we put forth the following hypotheses.

H1: There is a positive and significant impact of Ethical leadership on team effectiveness.

$\mathrm{H} 2$ : Emotional intelligence positively influences the relationship of ethical leadership and team effectiveness.

\section{METHODS AND ANALYSIS}

This chapter of the study explains explicit techniques or procedures which are used for identification, selection, process and evaluation of data and statistics of the subject matter. It also permits the researchers to critically assess the validity and reliability of the research work. The research methodology explicates the practice of scientific methods to investigate a variety of phenomenon related to any of the aspect of life including areas of science and those involving pure phenomenon (Mouton, 1996). There are scores of diverse approaches and techniques to conduct research on the subject matter. In general, the choice of these approaches and techniques is subjected to the underlying factor and the type of research that best fits the study material.

The unit of analysis for this study was middle level mangers or supervisors. It is because the unit of analysis needs to be carefully selected as a unit of analysis being the major and most significant entity fundamentally illustrates the element of research study. For example, any of the subsequent units might be a unit of analysis in the study. Individuals, groups, artifacts (books, photos, newspapers), 
geographical units (town, census tract, state) and social interactions (dyadic relations, divorces, arrests). The domain of this research work is service sector which further selects individuals from the middle level managers of consumers' banks. Moreover, geographically research study is narrowed down to twin cities i.e., Rawalpindi and Islamabad.

All the variables which are used in this research work have been assessed by applying diverse items from multiple studies. All the items have been measured by applying a five-point Likert-type scale which encompasses four parts such as Ethical Leadership as No 1, team Effectiveness as No 2 and Emotional Intelligence being No 3 whereas fourth part is consisting of demographics of the respondents. All the 252 respondents out of 300 respondents indicated their level of conformity with statements wherein 1 denotes Strongly Agree, 2 as Agree, 3 as Neutral, 4 as Disagree whereas 5 denotes as Strongly Disagree).

\section{Population and Sampling}

The target universe of the study is consisted of the middle level management of consumers' banks of twin cities i.e., Rawalpindi / Islamabad. Out of the target population the sample of 300 were selected based on the rule of thumb and research sampling formula. A total number of 300 respondents were approached by different means i.e., in person meetings, by email, and by WhatsApp. The heterogeneous population was consisting of males and females, performing their jobs at diverse hierarchical positions of management. However, the major portion of respondents was consisting of male members. Convenience sampling technique is applied to gather the data.

Banks have been preferred to delineate and assess the effect of emotional intelligence on team effectiveness under the umbrella of Ethical Leadership, whereas various categorized positions of bank officers are marked purposively as author of the study maintains extensive association and relations with the bankers working at diverse hierarchical positions from top executives to middle management. As title of the study itself speaks of its intention to probe into the research to dig out whether the impact of ethical leadership on team effectiveness, analyzing the role of emotional intelligence. So, all the diverse perspectives might be ascertained through the data collected from consumers' banks of the twin cities i.e., Islamabad and Rawalpindi. In this job bankers are required to be ethically strong and emotionally intelligent to deal with the clients on multiple ventures and thus they achieve the organizational objectives by enhancing their team effectiveness. Successful achievement of organizational goals ensures their climb to promotion ladder and get job satisfied.

In this study purposive sampling technique has been adopted. As mentioned in preceding paragraph that sample of this study comprised of the middle level management of consumers' banks of twin cities i.e., Rawalpindi / Islamabad. Almost 300 employees of middle level management cadre were touched by paying visits in person and some of them were logged on by email, and WhatsApp. Unit of analysis was individuals to maintain the fairness and to avoid the biasness. Each employee was administered with research questionnaire. Despite scores of visits to the banks in person, a very smaller number of employees were accessed in person whereas a big chunk of population was approached by mobile, WhatsApp and through email etc. Upon collection of responses of almost 252 employees out of 300 , same responses were entered on to SPSS in order to run miscellaneous statistical tests. After getting results from SPSS, interpretation of the data was conducted to reach to some conclusion and to prove the hypothesis. The sample size has been determined by using Krejci and Morgan (1970).

\section{Instrumentation}

In order to study effectively the impact of ethical leadership on team effectiveness; analyzing the role of emotional intelligence, a research questionnaire was adopted from formerly conducted studies and systematically and meticulously researched constructs. The entire questionnaire was further fragmented into three segments. The first segment of the questionnaire concentrated predominantly on the respondent's own perceived ethical leadership and how they assess and interpret it by themselves as a result of some ethical behaviors unanimously and globally consented upon. In this segment fifteen questions statements focusing on ethical leadership and based on these fifteen statements the feedback from the respondents was collected. The second segment of the questionnaire was comprised of eleven questions statements focusing principally on the team effectiveness. Based on eleven statements, the scenario was assessed about the features of a team member judgment of team effectiveness. The third 
segment of the questionnaire primarily deals with the emotional intelligence, and it is based on fifteen question statement.

The instrument of the study is comprised of four sections: section A deals with ethical leadership, section B deals with Team Effectiveness, and section three deals with Emotional Intelligence whereas section four describes personal information of the respondents. All the variables used in this research work were assessed by applying diverse items from multiple studies. All the items have been measured by applying a five-point Likert-type scale, where respondents indicated their level of conformity with statements wherein 1 denotes strongly disagree, 2 as agree, 3 as Neutral, 4 as Disagree whereas 5 denotes as strongly agree). Beside numerous personal visits to the respondents time and again for interviews, meetings and survey in order to gather data an electronic questionnaire was also developed for convenient access to the participants and being it the cost effective.

The additional motives behind the development of electronic questionnaire were that the research was supposed to be quantitative in nature and thus collection of data, its compilation and further its process in statistical tool SPSS stands much convenient if research instrument be developed in an electronic format. Thus, to measure the quantitative data, correlation analysis and regression instruments were applied.

A structured questionnaire was constructed in the basis of an extensive literature review. In particular, ethical leadership was measured using the Ethical Leadership scale (ELS) adopted from Brown et al. (2005). The instrument used to collect information is questionnaire adopted from Larson and LaFasto (1989) for team effectiveness, they have developed one such survey to assess a team's health and second source of questionnaire was taken from www.our-emotional-health.com about emotional intelligence.

\section{Response Rate}

In general research survey response rate is portrayed in percentage and researcher desires to obtain almost $60 \%$ response rate to reach to some valid conclusion of the study. However, response rate in respect of this study remained $84 \%$ as total 300 employees of middle level management was approached by using different medium but despite concerted efforts only 252 employees responded the research questionnaire.

Table 1 Response Rate

\begin{tabular}{ll}
\hline Questionnaire Floated & 300 \\
Returned & 265 \\
Response rate & $87.6 \%$ \\
Dropped Questionnaire & 13 \\
Finally Useable Questionnaire & 252 \\
\hline
\end{tabular}

\section{Reliability Statistics}

The concept of reliability in research is elucidated as the consistency of the measure and applied to assess the quality of research work. Moreover, it also specifies that how well a test or method measures the data. However, data is checked for the missing values or any of the inconsistencies found in the responses provided by the respondents. For the check, simple frequency runs are taken into consideration. The frequencies show that no omissions are found neither any value identified as missing. By finding the data cleaned, demographic characteristics are estimated by using SPSS-21. It is further followed by the correlation analysis which establishes the relationships and associations between the outcome variables and predictors.

At the end multiple regression approach is used to establish that how the predictive variable predicts of the outcome variable. Moreover, it also holds the analysis of the same statistical data in terms of descriptive statistics for all variables, its Demographics i.e., Gender, Age, Education, and experience, Variables, patterns, features and interpretation of all the numerical results. To assess and 
validate the hypothesis, correlation and regression in SPSS-22 has been used.

Reliability is defined as the ability of the measures to produce the consistent results in different conditions. Cronbach's (1951) alpha is used to test the reliability of the scales as measures of the study. The Cronbach's reliability index of all the variables considered are above 0.7 which shows that the instruments taken in the study are reliable. Reliability denotes the stability and dependability of a measure whereas; Validity is defined as the accuracy of the measure. Both concepts are used to evaluate the quality of research. They specify that how well a process, method, or test measure something.

\section{Table 2 Reliability Statistics}

\begin{tabular}{lll}
\hline Construct & Cronbach's Alpha & N of Items \\
\hline Ethical Leadership & .90 & 15 \\
Team Effectiveness & .79 & 11 \\
Emotional Intelligence & .88 & 15 \\
\hline
\end{tabular}

\section{Descriptive Statistics}

A Descriptive Statistics quantitatively explicates or encapsulate (summary statistic) patterns as shown in the below table:

Table 3 Consolidated Data of Demographics Variable

\begin{tabular}{|c|l|l|l|}
\hline $\begin{array}{c}\text { Demographics } \\
\text { Variables }\end{array}$ & \multicolumn{1}{|c|}{ Group } & Frequency & Percentage \\
\hline \multirow{5}{*}{ Age } & 20 Years Less & 21 & 8.3 \\
\cline { 2 - 4 } & $21-30$ & 115 & 45.6 \\
\cline { 2 - 4 } & $31-40$ & 65 & 25.8 \\
\cline { 2 - 4 } & $41-50$ & 39 & 15.5 \\
\cline { 2 - 4 } & Above 50 & 12 & 4.8 \\
\hline \multirow{4}{*}{ Gender } & Male & 176 & 69.8 \\
\cline { 2 - 4 } & Female & 76 & 30.2 \\
\hline \multirow{5}{*}{ Education } & Secondary School Certificate & 7 & 2.8 \\
\cline { 2 - 4 } & Higher Secondary School Certificate & 8 & 3.2 \\
\cline { 2 - 4 } & Bachelors & 86 & 34.1 \\
\cline { 2 - 4 } & Masters & 123 & 48.8 \\
\cline { 2 - 4 } & Doctorate or above & 28 & 11.1 \\
\hline \multirow{5}{*}{ Experience } & 5 Years or Less & 113 & 44.8 \\
\cline { 2 - 4 } & 6-10 & 69 & 27.4 \\
\cline { 2 - 4 } & $11-15$ & 29 & 16.3 \\
\cline { 2 - 4 } & 16 and above & 29 & 11.5 \\
\hline
\end{tabular}

\section{Correlation Analysis}

In the realm of statistics, the Pearson correlation coefficient is also known as the bivariate correlation, Pearson's r, the Pearson product-moment correlation coefficient (PPMCC), or informally as the correlation coefficient. It is a method of direct interaction between two data sets. It is the ratio between the covariance of two variants and the product of its standard deviation. So it is actually a standard measure of covariance, so that the result always has a value between and - and +1 . Where -1 is total negative correlation 1 is total positive correlation and 0 is no correlation. Like the covariance itself, the scale can only show a consistent and direct correlation of variability, and ignore several other forms of correlation or relationships. 
Table 4 Correlation Analysis

\begin{tabular}{llll}
\hline & $\begin{array}{l}\text { Ethical__ } \\
\text { Leadership }\end{array}$ & $\begin{array}{l}\text { Team__ } \\
\text { Effectiveness }\end{array}$ & $\begin{array}{l}\text { Emotional_ } \\
\text { Intelligence }\end{array}$ \\
\hline $\begin{array}{l}\text { Ethical__ } \\
\text { Leadership }\end{array}$ & 1 & & \\
$\begin{array}{l}\text { Team_- } \\
\text { Effectiveness }\end{array}$ & $.342^{* *}$ & 1 & \\
$\begin{array}{l}\text { Emotional_ } \\
\text { Intelligence }\end{array}$ & $.415^{* *}$ & $.513^{* *}$ & 1 \\
**. Correlation is significant at the 0.01 level (2-tailed) &
\end{tabular}

The result in table 4 demonstrates that ethical leadership maintains a significant relationship with dependent variable Team Effectiveness. Likewise Ethical leadership is also significantly related with emotional intelligence in a positive direction. Moreover, team effectiveness is also related with emotional intelligence, i.e. all the three variables are positively and are significantly correlated with each other. Ethical Leaders inspire normative social behavior and encourage such positive behaviors in their overall environs regardless of their management tiers. Hence, these leaders strongly disapprove unethical norms and conducts of any nature on the part of their colleagues and followers. They usually emphasis on specific responsibilities and practice award and punish system.

\section{Regression Analysis}

In the statistical jurisdiction, regression analysis is elucidated as collection of statistical procedures and practices which are used to measure the relationship between one or more independent variables and dependent variables. Broadly speaking, independent variables are also called as explanatory variables, covariates and predictors whereas dependent variables are known as 'response' or outcome variables. Regression analysis is a steady procedure to identify which variable maintains an effect on the topic of choice. The Regression process consents to positively decide what aspects matter considerably more, what aspects might be overlooked or disregarded, and further to this how all factors involved impact one another.

Linear regression is the most common type of regression, wherein a person finds a line that mostly suits the data in terms of a certain mathematical measure. Moreover, regression analysis is predominantly encompassing two conceptually dissimilar objectives. Firstly, its usage is substantially and significantly overlaps with the field of machine learning and extensively practices for forecasting and prediction. However, secondly, in few scenarios it may be practiced deducing causal relationships between the dependent and independent variables.

Significantly, regression by itself merely speaks of relationship between a set of independent variables and dependent variable in a fixed database. The researchers must prudently and cautiously rationalize that why the current relationship maintains the potential to predict a new context or why two variables have a causal effect between each other, in order to apply predictive regression or to indulge in causal relationships, respectively. The latter is particularly imperative when researchers measure causal relationships using observational data.

Table 5 Model Summary

\begin{tabular}{|c|c|c|c|c|c|c|c|c|c|}
\hline \multirow[t]{3}{*}{ Model } & \multirow[t]{3}{*}{$\mathrm{R}$} & \multirow{3}{*}{$\begin{array}{l}\mathrm{R} \\
\text { Square }\end{array}$} & \multirow{3}{*}{$\begin{array}{l}\text { Adjusted } \\
\text { R Square }\end{array}$} & \multirow{3}{*}{$\begin{array}{l}\text { Std. Error } \\
\text { the Estimate }\end{array}$} & \multicolumn{5}{|c|}{ of Change Statistics } \\
\hline & & & & & R Square & F Chang & df1 & df2 & Sig. \\
\hline & & & & & Change & & & & $\begin{array}{l}\text { F } \\
\text { Chan } \\
\text { ge }\end{array}$ \\
\hline 1 & $.532^{\mathrm{a}}$ & .283 & .278 & .44190 & .283 & 49.250 & 2 & 249 & .000 \\
\hline 2 & $.737^{\mathrm{b}}$ & .543 & .538 & .35344 & .260 & 141.246 & 1 & 248 & .000 \\
\hline
\end{tabular}

a. Predictors: (Constant), Ethical Leadership, Emotional Intelligence

b. Predictors: (Constant), Ethical Leadership, Emotional Intelligence, Int Term 
These results in Table 5 express that ethical leadership and emotional intelligence predicted team effectiveness positively. Adjusted R square is .278 with $\mathrm{F}$ change is 49.25 for model 1 and .538 with $\mathrm{F}$ change 141.246 for model 2. Both the models are significant on .000 levels.

\section{Analysis - ANOVA}

ANOVA (Variation Analysis) is an analytical and mathematical instrument which is used to determine whether the means of two or more groups are expressively dissimilar to on another. In addition, it segregates perceived aggregate variability (found inside a data set) into two categories: systematic elements and random elements. However, systematic elements maintain a statistical impact on a particular data set, while random element does not maintain any such impact. In a regression study, analysts apply the ANOVA test to assess the effect on the dependent variable by the independent variables. The one-way ANOVA is applied to three or more data groups, to obtain data about the relationship between independent and dependent variables.

Table 6 ANOVA ${ }^{\mathrm{a}}$

\begin{tabular}{lllllll}
\hline Model & & Sum of Squares & Df & Mean Square & F & Sig. \\
\hline 1 & Regression & 19.235 & 2 & 9.617 & 49.250 & $.000^{\mathrm{b}}$ \\
& Residual & 48.625 & 249 & .195 & & \\
& Total & 67.860 & 251 & & & \\
\hline 2 & Regression & 36.879 & 3 & 12.293 & 98.408 & $.000^{\mathrm{c}}$ \\
& Residual & 30.980 & 248 & .125 & & \\
& Total & 67.860 & 251 & & & \\
\hline
\end{tabular}

a. Dependent Variable: Team Effectiveness

b. Predictors: (Constant), Ethical Leadership, Emotional Intelligence

c. Predictors: (Constant), Ethical Leadership, Emotional Intelligence, Int Term

As mentioned in the above table, the F statistics of model 1 shows that the mean of Ethical Leadership (EL) and Emotional Intelligence (EI) maintains statistically significant difference from the team effectiveness $(\mathrm{TE})(\mathrm{F} 2,249=49.250, \mathrm{p}<0.001)$. Moreover, in model two with the interaction term it is also exhibiting the significance $(\mathrm{F} 3,248=98.408, \mathrm{p}<0.001)$. It further proves that the both models are demonstrating significant difference between the means of the variables. The above estimates direct us to run the regression analysis.

The coefficients in a linear regression, explains such factors that assists multiplication of the predictor values. The symbol of every single coefficient designates the track of the association amid a response and predictor variables. The simultaneous increase in predictor variable and the response variable signifies a positive sign.

The beta coefficient is defined as the rate of variation in the outcome variable with respect to each 1-unit variation in the predictive variable. Positive beta coefficient holds interpretation as with the change of each 1 unit of the predictor variable, similar and simultaneous increase happens in outcome variable. In the table 10 first sign is unstandardized beta B which symbolizes linear regression amid dependent and predictive variables. Thus, in terms of Variable 1, this represents that for each 1 unit increase in variable 1 , the dependent variable also gets increased by 1.57 units. The t-test evaluates whether the beta coefficient is significantly different from zero. So statistically insignificant $t$ value (beta coefficient) denotes the variable would not predict the outcome significantly. 
Table 7 Coefficients ${ }^{\mathrm{a}}$

\begin{tabular}{|c|c|c|c|c|c|c|}
\hline \multirow[b]{2}{*}{ Model } & & \multicolumn{5}{|c|}{$\begin{array}{r}\text { Standardized } \\
\text { Unstandardized Coefficients Coefficients }\end{array}$} \\
\hline & & $\bar{B}$ & Std. Error & Beta & $\mathrm{t}$ & Sig. \\
\hline \multirow[t]{3}{*}{1} & (Constant) & 1.007 & .121 & & 8.311 & .000 \\
\hline & Emotional Intelligence & .423 & .056 & .449 & 7.613 & .000 \\
\hline & Ethical Leadership & .154 & .058 & .155 & 2.635 & .009 \\
\hline \multirow[t]{4}{*}{2} & (Constant) & 1.848 & .120 & & 15.401 & .000 \\
\hline & Emotional Intelligence & .248 & .047 & .264 & 5.315 & .000 \\
\hline & Ethical Leadership & -.911 & .101 & -.920 & -9.015 & .000 \\
\hline & Int Term & .365 & .031 & 1.271 & 11.885 & .000 \\
\hline
\end{tabular}

Dependent Variable: Team Effectiveness

Dependent Variable: Team Effectiveness

In the above-mentioned table, both tables estimate the relationship of dependent and independent variables. These estimates provide with the amount of one unit increase in predictor affecting the dependent variables positively or negatively. With the estimations of model 1 , it is interpreted that all the coefficients are found statistically significant and demonstrate positive relationships. With the one unit increase in emotional intelligence, 0.423 -unit increase is predicted in team effectiveness. Similarly, a positively significant relationship is predicted of ethical leadership. It illustrates that with one unit increase in ethical leadership may result into .0154 unit increase in team effectiveness. However, after introducing the interaction term in model 2, ethical leadership exhibits significance level with negative relationship. It can be interpreted that Ethical leadership may have negative effect on team effectiveness.

\section{Hypotheses Testing}

Conclusively, three variables in to have been used in this study such as Ethical Leadership (EL) as independent variable, Team Effectiveness (TE) as dependent variable and Emotional Intelligence (EI). In order to verify the correlation between data collected and hypotheses of the study, Pearson correlation was employed in term of each variable just to discern the track of their association with respect to each other.

Table 8 Summary of Hypotheses

\begin{tabular}{|l|l|l|}
\hline No & Hypotheses & Status \\
\hline 1 & $\begin{array}{l}\text { H1 There is a positive and significant impact of Ethical } \\
\text { leadership on team effectiveness. }\end{array}$ & (Accepted) \\
\hline 2 & $\begin{array}{l}\text { H2 Emotional intelligence positively influences the } \\
\text { relationship of ethical leadership and team effectiveness }\end{array}$ & (Accepted) \\
\hline
\end{tabular}

In a nutshell the finding of the study validates the hypotheses that there is a positive as well as significant impact of ethical leadership on team effectiveness. In addition, by using emotional intelligence as a moderator variable in the relationship between ethical leadership and team effectiveness also indicates positive and significant relationship.

These hypotheses confirm that in the banking sector of twin cities, the ethical leadership of middle level managers and supervisors is very vital for the team effectiveness of the group members which indirectly affects the level of consumers' satisfaction. Moreover, the role of emotional intelligence in addition to ethical leadership is also significant in linking the two relationships. 


\section{CONCLUSION}

Organizational teams which are emotionally intelligent are more opt to actively participate in collaborative environs because they are more able to comprehend their emotions as well as emotions of their team members that enable them to regulate the emotions of their team member as well as themselves. Emotional intelligence in a team permits members to control their emotions as well as the emotions of their members that results in a building relationship of trust amongst each other. It also allows the team members to well communicate with each other and make decisions which are in the best interest of all team members.

Emotionally competent teams are better able to control their own emotions, comprehend the emotions of their team members, understanding the emotions of their group as whole, and finally use this information to assist guiding them through group process. An elevated degree of emotional intelligence facilitates diverse aspects of team process which include problem solving, high productivity, commitment, team effectiveness, interpersonal relationships and collaboration.

Keeping in view the role of emotional intelligence in an organizational framework this current study explores the impact of ethical leadership on team effectiveness, employing emotional intelligence as a moderator variable. To conduct this study Primary data is used. A sample of 300 respondents comprising of meddle level managers and supervisors of consumers' banks of Rawalpindi and Islamabad are attained. For statistical analysis standard regression analysis is used in the study. For the estimation SPSS software is used. The results of standards regression analysis depict the role of ethical leadership and emotional intelligence on team effectiveness is positive as well as significant at $5 \%$ level of significance. The results of F Stat delineate both models are significant and stable.

The result of ANOVA also elucidates that the mean of ethical leadership and emotional intelligence differs from each other at 5\% level of significance. In addition to this by including the interaction term in the second model, the significance level of the model also improved. It further proves that both models demonstrate as significant difference between their mean values which suggest that emotional intelligence act as the moderator variable in effecting the relationship between ethical leadership and team effectiveness. The results of our study are in consistent with the finding of Wang and Waldman (2014). The results of Pearson correlation coefficient also indicate a positive and significant correlation amongst ethical leadership, team effectiveness and emotional intelligence. The reliability of the three instruments used in this study is assessed through standard Cronbach's Alpha. Ethical leadership maintains .90 Cronbach's Alpha value whereas the value of Cronbach's Alpha for team effectiveness and emotion intelligence are .79 and .88 respectively. Since all these values are greater than .70 which explicitly demonstrates that the instruments are reliable. In a nutshell the finding of the study validates the hypotheses that there is a positive as well as significant impact of ethical leadership on team effectiveness. In addition, by using emotional intelligence as a moderator variable in the relationship between ethical leadership on team effectiveness also indicates positive and significant relationship.

\section{RECOMMENDATIONS FOR FUTURE RESEARCH}

Based on the findings of our study, the following recommendations for future work are suggested. Since we restricted our sample to only twin cities (Islamabad and Rawalpindi), however for later studies this sample size can be extended to other areas of Pakistan. Since the study focused on just banking sector particularly consumer banking of Pakistan for future studies other corporate sectors including telecom, IT, Energy and power, services sector etc. can be taken for future studies, the determinants of emotional intelligence, its parameters and other aspects which affect ethical leadership can be investigated.

This study can also be extended in analyzing leadership skills and team effectiveness in public sector institutions including numerous ministries, public sector enterprises, law enforcement agencies etc.

\section{REFERENCES}

Ahmad, S., Fazal-E-Hasan, S. M., \& Kaleem, A. (2018). How ethical leadership stimulates academics' retention in universities. International Journal of Educational Management, 32(7), $1348-1362$. 
Alegre, A., \& Levitt, K. (2014). The relation between emotional intelligence and transformational leadership: What do we really know? International Leadership Journal, 6(2), 61-101.

Anderson, N. R., \& West, M. A. (1994). The Team Climate Inventory: Manual and User's Guide. Windsor: ASE, NFER- elson.

Antonakis, J., Ashkanasy, N. M., \& Dasborough, M. T. (2009). Does leadership need emotional intelligence? The Leadership Quarterly, 20, 247-261.

Ashkanasy, N. M., \& Daus, C. S. (2005). Rumors of the death of emotional intelligence in organizational behavior are vastly exaggerated. Journal of Organizational Behavior, 26(4), 441 $-452$.

Ayoko, O. B., Callan, V. J., \& Härtel, C. E. (2008). The influence of team emotional intelligence climate on conflict and team members' reactions to conflict. Small Group Research, 39(2), 121149.

Balamohan, P., Tech, M., \& Gomathi, S. (2015). Emotional intelligence - Its importance and relationship with individual performance, team- effectiveness, leadership and marketing effectiveness. Mediterranean Journal of Social Sciences, 6(1), 120-128.

Bandura, A. (1986). Social foundations of moral thought and action: A Social Cognitive Theory. Englewood Cliffs, NJ: Prentice-Hall.

Bandura, A. (1991). W. M. Kurtines, \& J. L. Gewirtz (Eds.). Social Cognitive theory of moral thought and action. Handbook of moral Behaviour and Development, Hillsdale, NJ: Erlbaum, vol. 1, pp. 45-103.

Bar-On, R. (1997). The emotional quotient inventory (EQ-i). Technical manual.Toronto, Canada: Multi Health Systems.

Bass, B. M. (1990). From transactional to transformational leadership: Learning to share the vision. Organizational dynamics, 18(3), 19-31.

Bass, B. M., \& Steidlmeier, P. (1999). Ethics, Character and Authentic Transformational Leadership behaviour. The Leadership Quarterly, 10(2), 181-217.

Bass, B. M., \& Stogdill, R. M. (1990). Bass \&Stogdill's handbook of leadership: Theory, Research and Managerial Applications: Free Pr.

Bateman, B., Colin Wilson, F., \& Bingham, D. (2002). Team effectiveness - development of an audit questionnaire. Journal of Management Development, 21(3), 215-226.

Batool, B. (2013). Emotional intelligence and effective leadership. Journal of Business Studies Quarterly, 4(3), 84-94. Retrieved from http://jbsq.org/archives/

Bazerman, M. H. (2008). Evaluating Your Business Ethics: A Harvard professor explains why good people do unethical things. Gallup Management Journal Online, Gallup Poll News. Service. pp. $1-5$.

Bedi, A., Alpaslan, C. M., \& Green, S. (2016). A meta-analytic review of ethical leadership outcomes and moderators. Journal of Business Ethics, 139(3), 517-536. https://doi.org/10.1007/s10551015-2625-1

Blanchard, K. H., \& Peale, N. V. (1996). The power of ethical management: Ballantine Books.

Boyatzis, R. (2006). Using tipping points of emotional intelligence and cognitive competencies to predict financial performance of leaders. Psicothema, 18,124-131.

Brown, F. W., \& Moshavi, D. (2005). The incubator - Transformational leadership and emotional intelligence: A potential pathway for an increased understanding of interpersonal influence. Journal of Organizational Behavior, 26(7), 867-871.

Brown, M. E., \& Treviño, L. K. (2006). Ethical leadership: A review and future directions. Leadership Quarterly, 17(6), 595-616.

Brown, M. E., Treviño, L. K., \& Harrison, D. A. (2005). Ethical leadership: A social learning perspective for construct development and testing. Organizational Behavior and Human Decision Processes, 97(2), 117-134.

Cannon-Bowers, J. A., Tannenbaum, S. I., Salas, E., \& Volpe, C. E. (1995). Defining competencies and establishing team training requirements. Team effectiveness and decision making in organizations, 333, 380.

Caruso, D. R., \& Salovey, P. (2004). The emotionally intelligent manager: How to develop and use the four key emotional skills of leadership. John Wiley \& Sons.

Castellion, G. (1993). The wisdom of teams: Creating the high-performance organization by Jon R. 
Katzenbach and Douglas K. Smith. Boston, MA: Harvard Business School Press, Journal of Product Innovation Management, 10(3), 268-270.

Chang, A., Bordia, P., \& Duck, J. (2003). Punctuated equilibrium and linear progression: Toward a new understanding of group development. Academy of Management Journal, 48, 106-117.

Ciulla, J. B. (1995). Leadership Ethics: Mapping the Territory. Business Ethics Quarterly, 5(1), 5-28.

Cohen, S. G., \& Bailey, D. E. (1997). What makes teams work: Group effectiveness research from the shop floor to the executive suite. Journal of Management, 23(3), 239-290.

Cohen, S. G., Ledford, G. E., \& Spreitzer, G. M. (1996). A predictive model of self-managing work team effectiveness. Human Relations, 49(5), 643-676.

Côté, S., Lopes, P. N., Salovey, P., \& Miners, C. T. H. (2010). Emotional intelligence and leadership emergence in small groups. Leadership Quarterly, 21(3), 496-508.

Cummings, T. G. (1978). Self-Regulating Work Groups: A Socio-Technical Synthesis. Academy of Management Review, 3(3), 625-634.

Cyert, R. (1990). Defining leadership and explicating the process. Nonprofit Management Leadership, $1(1), 29-38$.

Dalla Costa, J. (1998). The ethical imperative: Why moral leadership is good business. Reading, MA: Addison-Wesley.

Darabi, M. (2012). Emotional Intelligence: A literature review. Journal of Applied Sciences Research, 8(6), 2991-2997.

Davison, R. (1997). 'An Instrument for Measuring Meeting Success', Information and Management, 32: $163-76$.

Davison, R. (1999). An instrument for measuring meeting success: Revalidation and modification. Information and Management, 36(6), 321-328.

DeGeorge, R. T. (1986). Business ethics. New York.

Den Hartog, D. N., \& De Hoogh, A. H. (2009). Empowering behaviour and leader fairness and integrity: Studying perceptions of ethical leader behaviour from a levels-of-analysis perspective. European journal of work and organizational psychology, 18(2), 199-230.

Dierendonck, D. V. (2011). Servant leadership: A review and synthesis. Journal of Management, 37(4), 1228-1261. doi:10.1177/0149206310380462

Downey, L. A., Lee, B., \& Stough, C. (2011). Recruitment Consultant Revenue: Relationships with IQ, personality, and emotional intelligence. International Journal of Selection an Assessment, 19(3), 280-286.

DuBrin, A. J. (2010). Principles of Leadership (6th ed.). Mason, OH: South-Western Cengage Learning.

Durán, A., Extremera, N., \& Rey, I. (2004). Self-reported emotional intelligence, burnout and engagement among staff in services for people with intellectual disabilities psychological reports, 95(2), 386-390.

Easterbrook, J. A. (1959). The effect of emotion on cue utilization and the organization of behavior. Psychological review, 66(3), 183.

Einarsen, S., Schanke-Aasland, M., \& Skogstad, A. (2007). Destructive leadership behavior: A definition and conceptual model. The Leadership Quarterly, 18(3), 207-216.

Elçi, M., Şener, İ., Aksoy, S., \& Alpkan, L. (2012). The Impact of Ethical Leadership and Leadership Effectiveness on Employees' Turnover Intention: The Mediating Role of Work Related Stress. Procedia - Social and Behavioral Sciences, 58, 289-297.

Emery, C. R., \& Barker, K. J. (2007). The effect of transactional and transformational leadership styles on the organizational commitment and job satisfaction of customer contact personnel. Journal of Organizational Culture, Communications and Conflict, 11(1), 77-90.

Enderle, G. (1987). Some perspectives of Managerial Ethical Leadership. Journal of Business Ethics, 6(8), 657-663.

Estrada, M., Monferrer, D., Rodríguez, A., \& Moliner, M. Á. (2021). Does emotional intelligence influence academic performance? The role of compassion and engagement in education for sustainable development. Sustainability (Switzerland), 13(4), 1-18.

Falk, C. F., \& Blaylock, B. K. (2012). The H factor: A behavioral explanation of leadership failures in the 2007-2009 financial system meltdown. Journal of Leadership, Accountability \& Ethics, $9(2), 68-82$. 
Farh, J. L., \& Cheng, B. S. (2000). A cultural analysis of paternalistic leadership in Chinese organizations. In Management and organizations in the Chinese context (pp. 84-127). Palgrave Macmillan, London

Feldman-Barrett, L., \& Salovey, P. (eds.). (2002). The wisdom in feeling: psychological processes in emotional intelligence. New York: Guilford Press.

Fernández-Berrocal, P., \& Extremera, N. (2006). Emotional intelligence: A theoretical and empirical review of its first 15 years of history. Psicothema, 18, 7-12.

Flood, P. C., Hannan, E., Smith, K. G., Turner, T., West, M. A., \& Dawson, J. (2000). Chief executive Leadership style, consensus decision making, and top management team effectiveness. European Journal of Work and Organizational Psychology, 9(3), 401-420.

Freeman, R. E., \& Stewart, L. (2006). Developing ethical leadership. Business Roundtable Institute for Corporate Ethics, 9

Friedlander, F. (1968). A Comparative Study of Consulting Processes and Group Development. The Journal of Applied Behavioral Science, 4(4), 377-399.

Fulmer, R. M. (2004). The challenge of ethical leadership. Organizational Dynamics, 33(3), 307-317.

Gardner, H. (1985). Frames of mind: The theory of multiple intelligences. Basic books. New York, 1985

Garfield, M. J., \& Dennis, A. R. (2013). Toward an integrated model of group development: Disruption of routines by technology-induced change. Journal of Management Information Systems, 29, 43-86.

Geher, G., \& Renstrom, K. L. (2004). Measurement issues in emotional intelligence research. In G. Geher (Ed.), Measuring emotional intelligence: Common ground and controversy (pp. 3-19).

George, J. M. (2000). Emotions and leadership: The role of emotional intelligence. Human Relations, 53(8), 1027-1055.

Gibson, C. B. (2003, October). Quality of Team Service: The Role of Field Independent Culture, Quality Orientation, and Quality Improvement Focus. Small Group Research. 